OPEN ACCESS

Edited by:

Xinran $\mathrm{Ma}$,

East China Normal University, China

Reviewed by:

Rita De Matteis,

University of Urbino Carlo Bo, Italy

Giulia Cantini,

University of Florence, Italy

${ }^{*}$ Correspondence:

Cheng-Chao Ruan

ruancc@fudan.edu.cn

Specialty section: This article was submitted to Cellular Endocrinology, a section of the journal

Frontiers in Endocrinology

Received: 12 January 2021 Accepted: 03 May 2021

Published: 25 May 2021

Citation:

Chen H-J, Meng T,

Gao P-J and Ruan C-C (2021)

The Role of Brown Adipose Tissue

Dysfunction in the Development

of Cardiovascular Disease.

Front. Endocrinol. 12:652246. doi: 10.3389/fendo.2021.652246

\section{The Role of Brown Adipose Tissue Dysfunction in the Development of Cardiovascular Disease}

\author{
Hong-Jin Chen ${ }^{1,2}$, Ting Meng ${ }^{3}$, Ping-Jin Gao ${ }^{1,2}$ and Cheng-Chao Ruan ${ }^{1,2,3 *}$ \\ 1 Department of Cardiovascular Medicine, State Key Laboratory of Medical Genomics, Shanghai Key Laboratory of \\ Hypertension, Department of Hypertension, Ruijin Hospital, Shanghai, China, ${ }^{2}$ Shanghai Institute of Hypertension, Shanghai \\ Jiao Tong University School of Medicine, Shanghai, China, ${ }^{3}$ Shanghai Key Laboratory of Bioactive Small Molecules, \\ Department of Physiology and Pathophysiology, School of Basic Medical Sciences, Fudan University, Shanghai, China
}

Brown adipose tissue (BAT), consisted of brown adipocytes and stromal vascular fraction, which includes endothelial cells, lymphocytes, fibroblasts and stem cells, plays a vital role in regulating cardiovascular health and diseases. As a thermogenic organ, BAT can influence body through strengthening energy expenditure by promoting glucose and lipid metabolism. In addition, BAT is also an endocrine organ which is able to secret adipokines in an autocrine and/or paracrine fashion. BAT plays a protective role in cardiovascular system through attenuating cardiac remodeling and suppressing inflammatory response. In this review, we summarize the advances from the discovery of BAT to the present and provide an overview on the role of BAT dysfunction in cardiovascular diseases.

Keywords: brown adipose tissue, cardiovascular diseases, obesity, adipokines, adipocyte

\section{INTRODUCTION}

Since 2000, the prevalence of obesity has risen sharply around the world. According to the research, a total of 108 million children and 604 million adults had been obese by 2015. Obesity accounted for 2.4 million deaths globally, and more than two thirds of deaths were due to cardiovascular disease (CVD), including hypertension, coronary heart disease and stroke (1). In particular, the accumulation of visceral fat can greatly increase the risk of death from CVD (2). These patients experience systemic changes, especially the change of white adipose tissue (WAT). WAT is a vital organ in energy storage, which can excessively accumulate in obese patients (3). The increase of WAT is the result of both hyperplasia and hypertrophy of adipocytes (4). In addition to WAT, there are two types of adipose tissue: brown adipose tissue (BAT) and beige adipose tissue. BAT merely represents $1-2 \%$ of fat, consisting of brown adipocytes and stromal vascular fraction (SVF), but it is vital in maintaining homeostasis. BAT has a crucial capacity for non-shivering thermogenesis in mammals, which is essential for survival in cold environment and consumption of excessive energy. Recently, research has found that BAT is not only significant in maintaining cardiovascular stability, but also recognized as a novel target to deal with obesity and other metabolic diseases, which attracts more and more attention. In this article, we review the development of BAT in animal models and human, discussing its relevance to cardiovascular damage. 


\section{DISCOVERY AND LOCATION OF BAT}

Early in 1551, BAT was first discovered in the scapula of a groundhog by Swiss naturalist Konrad Gessner, which was thought to be a gland associated with hibernation. It was not until twentieth century that BAT was considered as a mature tissue with certain component. Later, through necropsy studies, Heaton found BAT mainly located in (1) cervical/axillary (2), perirenal/ adrenal, and (3) around blood vessels. In addition, BAT was also found in the scapula of infants, which was the major location in rodents (5). In infants, BAT accounts for about $2-5 \%$ of body weight, while in adults, it only accounts for $0.05-0.1 \%$. The amount of BAT will decline with age, but it remains in specific areas of human body all the time. There are some researches showing that individuals exposed to cold will possess more BAT (6-8). However, lacking valid non-intervention means, the studies on BAT in vivo have been greatly limited for a long time. It was not until the application of positron emission tomography (PET) in combination with computer tomography (CT) that rekindled people's interest in BAT research. In 2009, three papers published in NEJM confirmed the presence of functional BAT in healthy humans, and the location was consistent with previous autopsy findings (9-11). Virtanen's research found a 15-fold increase in glucose intake in the cervical and supraclavicular regions of five participants exposed to cold (9). Cypess et al. reported that women possessed more BAT than men (10). According to the research, except for classic BAT, some BAT is mixed with WAT rather than presents alone (12). The aforementioned beige adipose tissue is also contained in WAT. Beige adipocytes intersperse within WAT, which can transforming into brown-like adipocytes under the certain stimulation such as cold exposure and beta adrenaline $(13,14)$. This process is named browning.

\section{THE ORIGIN OF BAT}

There was a research that researchers removed $40 \%$ BAT from young male rats surgically showing that the total mass, the oxidative and thermogenic capacity of BAT in experimental group was identical to control group after 9 days (15). There may be two possibilities. One is the functional compensation of remaining BAT. The other reason may be the differentiation of preadipocytes. A variety of researches have focused on the origin of BAT over the past decade. It is well-accepted that brown adipocytes share the same lineage with skeletal muscle cells. Pax3 and Pax7-expressing cells are confirmed to be the progenitor cells of skeletal muscle (16). And the function of Pax3 can be replaced by Pax7 mostly (17). Later in 2010, Pax7+ cells at embryonic day 9.5 (E9.5) can give rise to brown adipose tissue. While after E11.5, the Pax7 marked cells reduced drastically in BAT and then disappeared in E12.5 (18). As the embryo develops, Pax7-expressing cells become restricted to muscle-specific fate. Myf5 is also proved to be expressed in skeletal myogenic precursors previously, which plays an important role in myogenic determination (19). Then Myf5expressing cells were confirmed by Seale et al. that they could give rise to brown adipocytes in the development of classic BAT, beige adipocytes not included, while Myf5 mRNA was not found in mature BAT (20). Brown adipocytes arise from multiple lineages. Classic brown adipocytes are mentioned above that they are broadly believed from Pax7/Myf5 progenitor cells, while these genes just expressing transiently in the development of BAT. Activated beige adipocytes are similar to brown adipocytes. They are distributed in many areas, including WAT, PVAT and so on. Thereinto, SM22 $\alpha$ is reported to take part in the development of perivascular adipocytes transiently (21). Recent research shows that the adipocytes in thoracic aorta perivascular adipose tissue (T-PVAT) have different cell lineages. In this research, T-PVAT is divided into anterior T-PVAT (A-T-PVAT) and lateral T-PVAT (L-T-PVAT), and the results suggest that A-T-PVAT adipocytes are derived from SM22 $\alpha$ progenitors while L-T-PVAT adipocytes are originated from cells containing both SM22 $\alpha$ and Myf5 (22). Different sources of adipose cells may indicate they will play different roles in maintaining body homeostasis.

\section{FUNCTIONS OF BAT}

\section{Metabolic Function of BAT}

Since its discovery, BAT, as a thermogenesis organ, has been linked to heat production, which is regulated by the sympathetic nervous system. Thermogenesis is a manifestation of metabolic process containing shivering thermogenesis and non-shivering thermogenesis. Thereinto, shivering thermogenesis is the main contributor to heat generation under the circumstance of extreme cold. It is the result of involuntary contraction of skeletal muscles (23), and this process requires a lot of energy, causing discomfort and fatigue. Non-shivering thermogenesis under cold stimulation is to activate sympathetic nervous system to promote BAT heat production (24). Inhibiting the thermogenic function of BAT by using nicotinic acid led to increased muscle contraction against cold temperature, which demonstrated that BAT plays an important role in maintaining a normal body temperature in cold (25). Brown adipocytes with multilocular lipid droplets, are rich in mitochondria, and can significantly express uncoupling protein 1 (UCP1), PGC1 $\alpha$, PR domain-containing protein 16 (PRDM16) $(26,27), \beta 3$-adrenoceptor and other genes related to thermogenesis. Activated BAT expresses $\beta 3$ adrenoreceptors which mediate the sympathetic drive to mobilize and upregulate UCP1 to promote a large amount of energy loss in the form of heat energy (28). Thus BAT plays a vital role in body energy expenditure through increasing glucose metabolism and lipid metabolism, which may be a valuable therapeutic approach to metabolism-related diseases, such as obesity. According to the research, nearly $40 \mathrm{~g}$ totally activated BAT in man could correspond to as much as $20 \%$ of body energy expenditure over a year, which is equivalent to $20 \mathrm{~kg}$ of body weight (29). Hence BAT is an important regulator not only in energy metabolism, but in the lipid and glucose metabolism and these two aspects are interrelated. Free fatty acids are the main source of oxidation in BAT to produce heat which is from the lipolysis of the triglyceride (TG) in lipid droplets in adipocytes. With the oxidation of fatty acids, reduced TG needs to be restored through the uptake of glucose and albumin-bound free fatty acid in the plasma (30) in order to provide the source of mitochondrial 
oxidation. Thus activated BAT has its place in the clearance of glucose and TG in the plasma $(31,32)$. According to the research, the utilize of glucose in BAT accounts for nearly $1 \%$ of the total body glucose use, and that is about $5 \mathrm{~g}$ of glucose in a healthy individual (33). Disordered glucose and lipid metabolism including decreased high-density lipoprotein (HDL-C), increased triglyceride-rich lipoprotein and insulin resistance are important risk factors for CVD (34). As mentioned above, BAT accounts for $0.05-0.1 \%$ of body weight in adults. Thus a healthy adult possesses nearly $40 \mathrm{~g}$ BAT, which plays a vital role in balancing body energy, lipid and glucose metabolism.

\section{Secretion Function of BAT}

Apart from thermogenesis, BAT has gradually attracted more attention as a secretory organ. Before that, a number of WATsecreted molecules, which are called adipokines, have been identified in recent years, including inflammatory cytokines, leptin and so on. However, these adipokines are rarely expressed in BAT, which led the researchers to think that BAT has limited function of secretion (35). Recent years, the application of proteomics analysis in BAT researches provides researchers with an effective method to discover new cytokines. Ail et al. found fibroblast growth factor 21 (FGF21), interleukin-6 (IL-6), neuregulin-4 (NRG4) and vascular endothelial growth factor A (VEGFA), expressed in BAT will involve in thermogenesis, angiogenesis and the browning of WAT in an autocrine and/or paracrine fashion (36-40). Brown adipokines, they mainly act on different tissues or target organs to protect or regulate the cardiovascular system. For example, FGF21 is shown to have an important protective effect on the heart (41); IL-6, whose concentration is usually considered as indication of inflammatory response (42), has a positive function on regulating the glucose metabolism of BAT working together with FGF21 $(43,44)$ and the function of anti-inflammation (45). In addition, IL-6 can perform completely different function depending on cell type and context; bone-morphogenetic protein $8 \mathrm{~b}$ (BMP8b) takes part in the neurovascular remolding (46); NRG4 has a negative relation with acute coronary syndrome (ACS) (47); C-X-C motif chemokine ligand-14 (CXCL14) and growth differentiation factor 15 (GDF15) participate in anti-inflammation process $(48,49)$. Furthermore, there are several bioactive lipid termed lipokines from both WAT and BAT, which also play an important role in the regulation of cardiovascular health. Recently, a novel lipokine derived from BAT, 12,13-dihydroxy-9Z-octadecenoic acid (12,13-diHOME), has been confirmed to play a positive role in cardiac function (50). However, further research is needed on the discovery and characteristics of the new cytokines derived from brown adipocytes. The important factors, which have been found discovered so far, are listed in Table $\mathbf{1}$.

\section{BAT AND CARDIOVASCULAR DISEASES}

The relationship between obesity and cardiovascular diseases has received much attention since last century (51). Multiple epidemiological investigations indicate that obesity is the major determinant of cardiovascular diseases especially in adolescents
(52). More than $75 \%$ high blood pressure is caused by obesity directly (53). A large number of studies have reported that there are structural and functional heart abnormalities in obese subjects, such as left atrium enlargement and left ventricular hypertrophy (54-56). There are also some researches showing that the activity of BAT will decline in obesity (57), which may reveal that BAT plays a positive role in health maintaining (Figure 1). Active BAT may promote cardiac metabolic health through the combustion of triglycerides and glucose derived free fatty acids, thus preventing adipose tissue dysfunction, obesity and insulin resistance (58). As early as the twentieth century, Cittadini et al. developed obese mice based on the ablation of BAT by transgenic technology to study the relationship between BAT and CVD. In their research, they found these knockout mice had decreased energy-expenditure, and hyperphagia leading to obesity, composed with decreased body temperature and metabolic rate. Their follow-up research showed that in addition to the development of obesity and insulin resistance, the ablation of BAT led to the elevation of blood pressure, left ventricular hypertrophy with an eccentric remodeling pattern and increased interstitial tissue (59). In clinical research, Richard and his group's data obtained from the follow-up investigation of 443 patients indicated that the activity of BAT had a negative relationship with vascular inflammation and CVD (60). And the beneficial effects of BAT on improving blood glucose, TG and HDL play an significant role in promoting cadiometabolic health (61). The next question for the researchers is how BAT is involved into the occurrence and development of CVD.

\section{BAT and Vascular Injury}

Vascular injury refers to the structural damage or dysfunction of blood vessel caused by mechanical or chemical stimulation in vitro or in vivo. And atherosclerosis and aorta aneurysm, considered as the two most common and dangerous human diseases, are given serious attention.

Atherosclerosis is associated with a chronic inflammation reaction, including the accumulation of lipid, infiltration of inflammatory cells, proliferation, migration of smooth muscle cells, oxidative stress and neovascularization. Obesity is a recognized risk factor for atherosclerosis. Adipose tissue, including WAT,BAT and thoracic and abdominal PVAT, play an important role in the occurrence and development of atherosclerosis. It is traditionally believed that the increased low density lipoprotein (LDL) in the blood of obese people, which is deposited on the wall of blood vessels, then swallowed by macrophage and finally forms the foam cells, is the key step in the formation and development of atherosclerosis (62). However, recent researches show that the formation of atherosclerotic plaque is initially due to endothelial dysfunction, which is associated with infiltration of inflammatory cells, caused by the pro-inflammatory factor secreted by adipose tissue $(63,64)$. In animal studies, researchers use beta-adrenaline to induce browning of adipose tissue. Increased BAT can slow the development of hypercholesterolaemia and atherosclerosis in hyperlipidemia mice (65). Mitochondria are abundant in BAT, which can synthesize and release peroxisome proliferator-activated receptor gamma coactivator- $1 \alpha$ (PGC-1 $\alpha$ ) to assist carbon monoxide to complete vasodilation. The decreased BAT results in the insufficient synthesis 
TABLE 1 | Major factors expressed by adipose tissue and their important and putative functions.

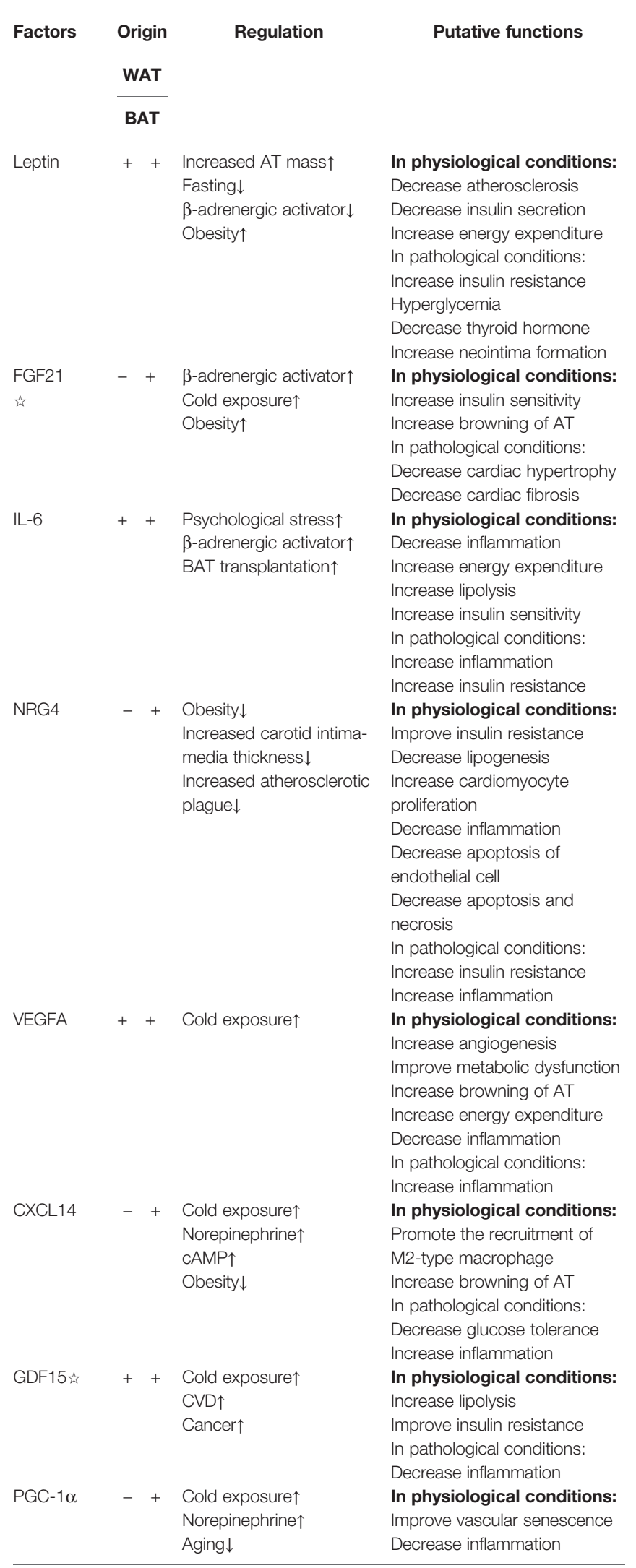

(Continued)
TABLE 1 | Continued

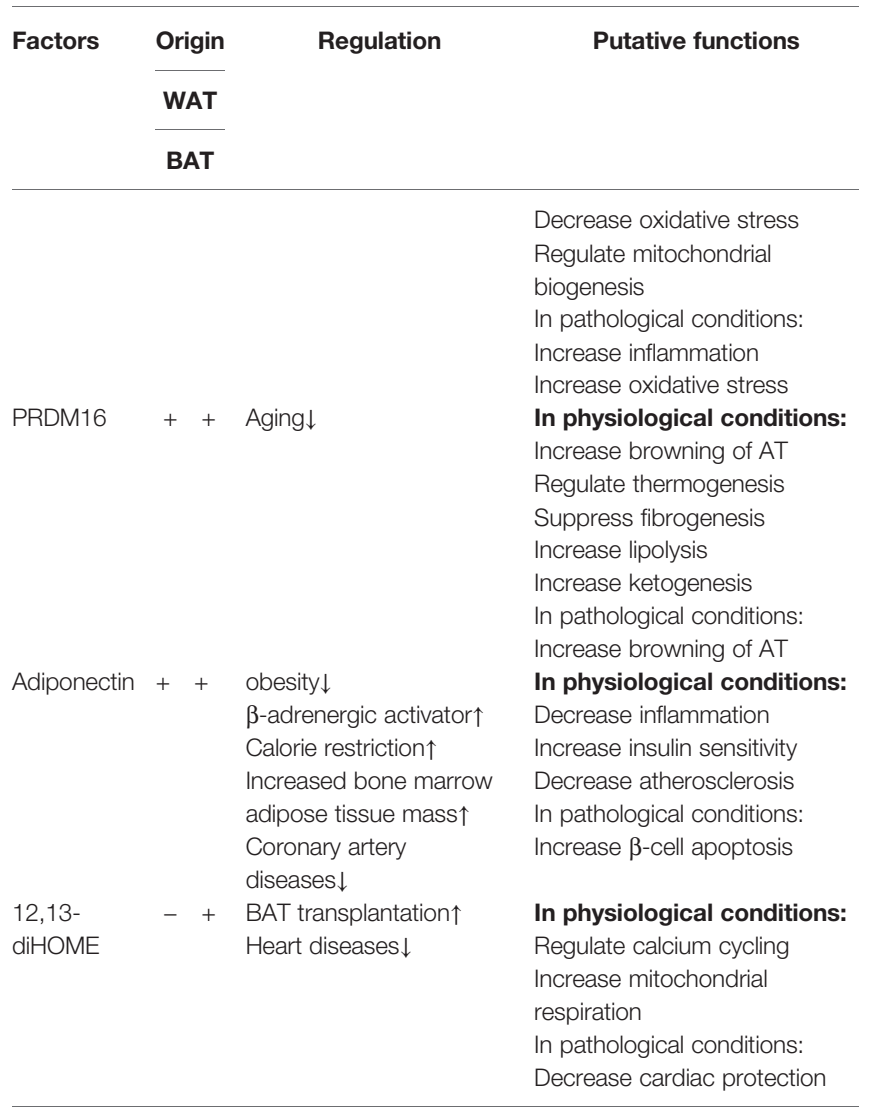

- represents this factor is not expressed or rare expressed in the tissue; + represents this factor is expressed in physical condition or certain conditions. Most factors listed above play a protective role in physiological conditions, and their expression decrease in pathological conditions which leads to bad results as showed in "in pathological conditions" column. "** means the expression of these factors will increase early in pathological conditions and then exert protective effects.

of PGC- $1 \alpha$ and then impairs vasodilation seriously (66). In addition, PGC-1 $\alpha$ plays a vital role in the biosynthesis and function of mitochondria, and the dysfunction of mitochondria will cause a series of problems including telomere dysfunction, DNA damage and oxidative stress (67). There are also evidence showing that PGC- $1 \alpha$ can regulate vascular senescence negatively (68). In the study of atherosclerosis, there are researches showing that the BAT-derived exosome can inhibit the increase of miR-324-5p, which is the specific biomarker of the development of atherosclerosis (69). There are also many other BAT-derived cytokines involved in vascular health. Adiponectin, for example, which is produced by adipose tissue and enters into the circulation, was suggested to fight against atherosclerosis through suppressing endothelial inflammation and VSMC proliferation. Besides, it can restrain the transformation of macrophage to foam cells (70). Apart from BAT, the adipose tissue around vessels, which is called perivascular adipose tissue (PVAT), also plays a vital role in protecting vessels. PVAT, especially thoracic PVAT, similar to BAT, is a thermogenesis organ, which is crucial for maintenance of intravascular temperature. The activation of PVAT can attenuate the development of atherosclerosis, through preventing intravascular temperature loss which can directly maintenance the function of endothelial. Furthermore, thermogenic activation of 


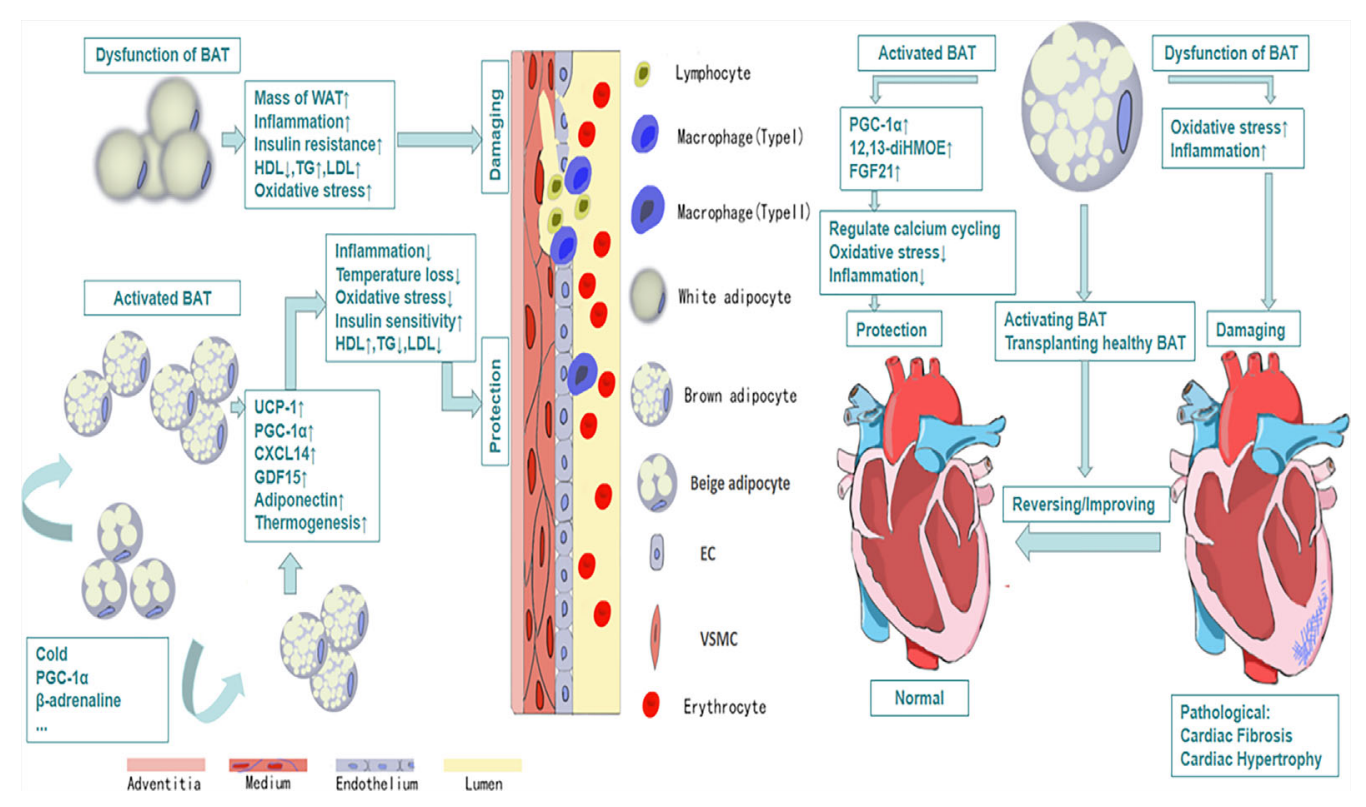

FIGURE 1 | The protective efforts of BAT on vessels and heart. Activated BAT, including classic BAT and the BAT derived from the browning of beige adipocytes under the condition of cold exposure, beta-adrenaline stimulation and so on, plays a protective role through its metabolic function and secretion function, which leads to decreased inflammation, decreased oxidative stress response and increased HDL, increased uptake of glucose and so on. And all of these contribute to cardiovascular health and vice versa.

PVAT can enhance the clearance of total lipid. While this protection will disappear when PVAT is removed (21). In addition, there is an underestimated type of adipose tissue, called epicardial adipose tissue (EAT), increasing of whose mass is considered as a risk factor for the development of coronary artery diseases (71). EAT is considered as a type of beige adipose tissue with overexpression of UCP-1, the marker of brown adipose tissue, relative to WAT (72). Akin to PVAT, EAT possesses significant thermogenic capacity, sharing a negative association with temperature, and plays an important role in protecting cardiovascular health. $\alpha 2 \mathrm{~A}$-adrenergic receptor (ADRA2A) is an inhibitory $\alpha$-adrenergic receptor, which is at a lower level compared to WAT and it may contribute to the higher signaling via $\beta$-adrenergic receptors in EAT. Besides, through adding conditioned media which was collected from EAT treated with isoproterenol to primary human cardiac endothelial cell and then culturing it for $24 \mathrm{~h}$, significant down-regulation of the expression of adhesion markers such as Icam 1 and Vcam 1 in endothelial cells were detected compared to control group (73). Thus abnormal EAT affected the function of endothelial cells seriously which is considered as the initial pathological process in the development of atherosclerosis. What's more, research reported that activated EAT was associated with decreased circulating TG levels and increased HDL-C levels which had protective effect on atherosclerosis (72). In conclusion, in obesity, increased fatty acid release by WAT and decreased lipid combustion by BAT and thoracic PVAT lead to hyperlipidemia, which contributes to atherosclerosis development. Besides, obese WAT and abdominal PVAT release proinflaammatory factors that further promote atherosclerosis (74).

Aortic aneurysm (AA), defined as a pathological and progressive dilation of a segment of a blood vessel, is a common and dangerous vascular disease, especially abdominal aortic aneurysm (AAA). There is still lacking effective means of medical treatments. For the pathogenesis of AA, the mainstream view is that decreased smooth muscle cells, the degradation of cell matrix and infiltration of inflammatory cells in the blood vessel result in the thinning of adventitia and media jointly (75). The high risk of cardiovascularrelated death in obesity is due to the AA partly (76). In the research, researchers found obesity could increase the morbidity of AngIIinduced AA and exacerbate perivascular infiltration of macrophage and expression of MCP-1, IL-6, chemotactic factors and so on. In addition, they found there were more brown adipocytes around thoracic aorta, while more white adipocytes around abdominal aorta. Thus they finally draw the conclusion that in obesity, the high incidence of AA, especially AAA, is critically due to the decreased BAT which aggravates vascular inflammation rather than changes cholesterol concentration, distribution of lipoprotein and insulin resistance in blood (77). Dowal and his group confirm that BAT has ability to repress the inflammatory action of macrophage (78). Further research shows that BAT can inhibit inflammation to protect blood vessels through following two aspects at least. On the one hand, BAT-derived CXCL14 can recruit M2 macrophage possessing anti-inflammation ability (48). On the other hand, BAT can secrete GDF15 which acts on M1 macrophage to inhibit its proinflammation response (49).

In summary, the capacity of BAT in vascular protection is now widely recognized to be multifaceted from its original thermogenic function to its powerful endocrine function and metabolic function. And its anti-inflammation function and the ability to improve lipid, glucose metabolism can prevent of reverse vascular diseases directly or indirectly. 


\section{BAT and Heart Diseases}

Heart failure, as the terminal state of kinds of heart diseases, with high mortality and bad prognosis, is a clinical syndrome caused by the structural or functional abnormalities of the heart. It is a progressive disease, from initial myocardial damage to the damage of ventricular filling and cardiac ejection, and then to ventricular remolding finally. Recent research shows that adipose tissue-derived cytokines take part in the regulation of heart diseases (79). In animal study, removing BAT in the body will aggravate cardiac remolding, which appears BAT may play a role in cardiac protection in some way. FGF21, as one of the first proven cytokines from BAT, has a protective effect on the heart. And in the follow-up study, activation of adenosine 2A (A2A) receptor in BAT can mediate BAT secrete FGF21, which can attenuate hypertensive cardiac remolding (80). In addition, mice with UCP-1 knockout had severe myocardial injuries, fibrosis and ventricular remolding when they were given heart injury in experiments, and their survival rate was significant reducing. However, transplanting BAT from healthy mice could reverse heart damage and improve survival (81). As is mentioned above, PGC- $1 \alpha$ plays an important role in vascular protection. It is essential for heart protection as well. The dysfunction of BAT results in the decrease of PGC- $1 \alpha$ synthesis. In some patients with cardiac hypertrophy caused by hypertension or heart failure, it was found that reduced PGC- $1 \alpha$ would lead to the decrease of the oxidation of fatty acid and the suppression in mitochondrial oxidative phosphorylation (82). While the exact mechanisms have not been elucidated. Some researches show that BAT can inhibit NF- $\kappa B$ through SIRT1-PGC1 $\alpha$-PPAR $\gamma$ pathway to suppress inflammation (83). What's more, Pinckard et al. found that the transplantation of BAT could reverse cardiac dysfunction and cardiac remodeling caused by high-fat diet through increase the expression of 12,13-diHOME. Further research showed that 12,13diHOME together with NOS1 could enhance cardiac function by regulating the calcium cycling (50). In addition, the dysfunction of adipose tissue has been discussed on a variety of cardiac disorders in many researches (84).

\section{The Negative Effect of BAT}

There are a number of studies showing that BAT plays a positive role in cardiovascular damage. While some researches show that activated BAT and increased browning of WAT may exacerbate atherosclerosis $(85,86)$. Activated BAT and increased beige adipose tissue can elevate lipolysis and thermogenesis, then increase bio-synthesis of cholesterol and mobilization of low

\section{REFERENCES}

1. GBD 2015 Obesity Collaborators, Afshin A, Forouzanfar MH, Reitsma MB, Sur P, Estep K, et al. Health Effects of Overweight and Obesity in 195 Countries Over 25 Years. N Engl J Med (2017) 377(1):13-27. doi: 10.1056/ NEJMoa1614362

2. Després JP, Moorjani S, Lupien PJ, Tremblay A, Nadeau A, Bouchard C. Regional Distribution of Body Fat, Plasma Lipoproteins, and Cardiovascular Disease. Arteriosclerosis (1990) 10(4):497-511. doi: 10.1161/01.atv.10.4.497

3. Rosen ED, Spiegelman BM. Adipocytes as Regulators of Energy Balance and Glucose Homeostasis. Nature (2006) 444(7121):847-53. doi: 10.1038/nature05483 density lipoprotein (LDL) and very low density lipoprotein (VLDL), which promotes the growth of atherosclerotic plague. In their further study, they found genetic deletion of UCP1 in ApoE(-/-) mice, which is the specific marker of BAT, could prevent the occurrence of the above phenomenon.

\section{CONCLUSION}

It is widely accepted that obesity can induce and accelerate the progression of CVD. Traditionally, the accumulation of WAT in obese people was considered as the major factor that increases the morbidity of CVD, while the role of BAT in obesity has been paid much more attention recently. In the past, due to the lack of accurate detection methods, the clinic value of BAT has been greatly underestimated. With the development of technology, such as the application of PET/CT, BAT is strongly associated with health. After kinds of studies, BAT is considered as not only a thermogenic organ, but also a endocrine organ. It has a powerful anti-inflammatory effect which plays an important role in cardiovascular protection. As a bridge between CVD and metabolic diseases, BAT will provide new ideas for the treatment. While recent researches show activated BAT is not as good as we thought before, which can accelerate the formation of atherosclerosis. So BAT might be a double-edged sword in the development of CVD and the exact mechanism of BAT has not been understood yet. Thus developing its positive function fully and reducing its possible negative effects are the direction we should strive for in the future, and it needs further elaboration of its possible mechanism in the development of CVD.

\section{AUTHOR CONTRIBUTIONS}

$\mathrm{C}-\mathrm{CR}$ and $\mathrm{H}$-JC designed the study and wrote the manuscript. TM and P-JG performed critical revision of the manuscript. All authors contributed to the article and approved the submitted version.

\section{FUNDING}

This work was supported by the National Natural Science Foundation of China (81922004, 81770495, 91739303, 81870180 and 81700433$)$ and the Natural Science Foundation of Shanghai, China (19JC1414600).

4. Hirsch J, Batchelor B. Adipose Tissue Cellularity in Human Obesity. Clin Endocrinol Metab (1976) 5(2):299-311. doi: 10.1016/s0300-595x(76)80023-0

5. Heaton JM. The Distribution of Brown Adipose Tissue in the Human. J Anat (1972) 112(Pt 1):35-9.

6. Huttunen P, Hirvonen J, Kinnula V. The Occurrence of Brown Adipose Tissue in Outdoor Workers. Eur J Appl Physiol Occup Physiol (1981) 46 (4):339-45. doi: 10.1007/BF00422121

7. van Ooijen AM, van Marken Lichtenbelt WD, van Steenhoven AA, Westerterp KR. Seasonal Changes in Metabolic and Temperature Responses to Cold Air in Humans. Physiol Behav (2004) 82(2-3):545-53. doi: 10.1016/j.physbeh.2004.05.001 
8. Nishimura T, Motoi M, Egashira Y, Choi D, Aoyagi K, Watanuki S. Seasonal Variation of Non-Shivering Thermogenesis (NST) During Mild Cold Exposure. J Physiol Anthropol (2015) 34(1):11. doi: 10.1186/s40101-0150051-9

9. Virtanen KA, Lidell ME, Orava J, Heglind M, Westergren R, Niemi T, et al. Functional Brown Adipose Tissue in Healthy Adults. N Engl J Med (2009) 360 (15):1518-25. doi: 10.1056/NEJMoa0808949

10. Cypess AM, Lehman S, Williams G, Tal I, Rodman D, Goldfine AB, et al. Identification and Importance of Brown Adipose Tissue in Adult Humans. $N$ Engl J Med (2009) 360(15):1509-17. doi: 10.1056/NEJMoa0810780

11. van Marken Lichtenbelt WD, Vanhommerig JW, Smulders NM, Drossaerts JM, Kemerink GJ, Bouvy ND, et al. Cold-Activated Brown Adipose Tissue in Healthy Men. N Engl J Med (2009) 360(15):1500-8. doi: 10.1056/ NEJMoa0808718

12. Cypess AM, White AP, Vernochet C, Schulz TJ, Xue R, Sass CA, et al. Anatomical Localization, Gene Expression Profiling and Functional Characterization of Adult Human Neck Brown Fat. Nat Med (2013) 19 (5):635-9. doi: 10.1038/nm.3112

13. Granneman JG, Li P, Zhu Z, Lu Y. Metabolic and Cellular Plasticity in White Adipose Tissue I: Effects of Beta3-Adrenergic Receptor Activation. Am J Physiol Endocrinol Metab (2005) 289(4):E608-16. doi: 10.1152/ajpendo. 00009.2005

14. Himms-Hagen J, Melnyk A, Zingaretti MC, Ceresi E, Barbatelli G, Cinti S. Multilocular Fat Cells in WAT of CL-316243-Treated Rats Derive Directly From White Adipocytes. Am J Physiol Cell Physiol (2000) 279(3):C670-81. doi: 10.1152/ajpcell.2000.279.3.C670

15. Rothwell NJ, Stock MJ. Surgical Removal of Brown Fat Results in Rapid and Complete Compensation by Other Depots. Am J Physiol (1989) 257(2 Pt 2): R253-8. doi: 10.1152/ajpregu.1989.257.2.R253

16. Relaix F, Rocancourt D, Mansouri A, Buckingham M. A Pax3/Pax7Dependent Population of Skeletal Muscle Progenitor Cells. Nature (2005) 435(7044):948-53. doi: 10.1038/nature03594

17. Relaix F, Rocancourt D, Mansouri A, Buckingham M. Divergent Functions of Murine Pax3 and Pax7 in Limb Muscle Development. Genes Dev (2004) 18 (9):1088-105. doi: 10.1101/gad.301004

18. Lepper C, Fan CM. Inducible Lineage Tracing of Pax7-Descendant Cells Reveals Embryonic Origin of Adult Satellite Cells. Genesis (2010) 48(7):42436. doi: $10.1002 /$ dvg. 20630

19. Tallquist MD, Weismann KE, Hellström M, Soriano P. Early Myotome Specification Regulates PDGFA Expression and Axial Skeleton Development. Development (2000) 127(23):5059-70. doi: 10.1242/dev.127.23.5059

20. Seale P, Bjork B, Yang W, Kajimura S, Chin S, Kuang S, et al. PRDM16 Controls a Brown Fat/Skeletal Muscle Switch. Nature (2008) 454(7207):961-7. doi: 10.1038/nature07182

21. Chang L, Villacorta L, Li R, Hamblin M, Xu W, Dou C, et al. Loss of Perivascular Adipose Tissue on Peroxisome Proliferator-Activated Receptor$\Gamma$ Deletion in Smooth Muscle Cells Impairs Intravascular Thermoregulation and Enhances Atherosclerosis. Circulation (2012) 126(9):1067-78. doi: 10.1161/CIRCULATIONAHA.112.104489

22. Ye M, Ruan CC, Fu M, Xu L, Chen D, Zhu M, et al. Developmental and Functional Characteristics of the Thoracic Aorta Perivascular Adipocyte. Cell Mol Life Sci (2019) 76(4):777-89. doi: 10.1007/s00018-018-2970-1

23. Haman F, Blondin DP. Shivering Thermogenesis in Humans: Origin, Contribution and Metabolic Requirement. Temperature (Austin) (2017) 4 (3):217-26. doi: 10.1080/23328940.2017.1328999

24. SMITH RE, ROBERTS JC. Thermogenesis of Brown Adipose Tissue in ColdAcclimated Rats. Am J Physiol (1964) 206:143-8. doi: 10.1152/ajplegacy. 1964.206.1.143

25. Blondin DP, Frisch F, Phoenix S, Guérin B, Turcotte ÉE, Haman F, et al. Inhibition of Intracellular Triglyceride Lipolysis Suppresses Cold-Induced Brown Adipose Tissue Metabolism and Increases Shivering in Humans. Cell Metab (2017) 25(2):438-47. doi: 10.1016/j.cmet.2016.12.005

26. Seale P, Kajimura S, Yang W, Chin S, Rohas LM, Uldry M, et al. Transcriptional Control of Brown Fat Determination by PRDM16. Cell Metab (2007) 6(1):38-54. doi: 10.1016/j.cmet.2007.06.001

27. Wang W, Ishibashi J, Trefely S, Shao M, Cowan AJ, Sakers A, et al. A PRDM16-Driven Metabolic Signal From Adipocytes Regulates Precursor Cell Fate. Cell Metab (2019) 30(1):174-89.e5. doi: 10.1016/j.cmet.2019.05.005
28. Bhatt PS, Dhillo WS, Salem V. Human Brown Adipose Tissue-Function and Therapeutic Potential in Metabolic Disease. Curr Opin Pharmacol (2017) 37:1-9. doi: 10.1016/j.coph.2017.07.004

29. Rothwell NJ, Stock MJ. Luxuskonsumption, Diet-Induced Thermogenesis and Brown Fat: The Case in Favour. Clin Sci (Lond) (1983) 64(1):19-23. doi: $10.1042 / \mathrm{cs} 0640019$

30. Maliszewska K, Kretowski A. Brown Adipose Tissue and Its Role in Insulin and Glucose Homeostasis. Int J Mol Sci (2021) 22(4):1530. doi: 10.3390/ ijms22041530

31. Wu MV, Bikopoulos G, Hung S, Ceddia RB. Thermogenic Capacity is Antagonistically Regulated in Classical Brown and White Subcutaneous Fat Depots by High Fat Diet and Endurance Training in Rats: Impact on WholeBody Energy Expenditure. J Biol Chem (2014) 289(49):34129-40. doi: 10.1074/jbc.M114.591008

32. Burcelin R, Kande J, Ricquier D, Girard J. Changes in Uncoupling Protein and GLUT4 Glucose Transporter Expressions in Interscapular Brown Adipose Tissue of Diabetic Rats: Relative Roles of Hyperglycaemia and Hypoinsulinaemia. Biochem J (1993) 291(Pt 1):109-13. doi: 10.1042/ bj2910109

33. Blondin DP, Labbé SM, Noll C, Kunach M, Phoenix S, Guérin B, et al. Selective Impairment of Glucose But Not Fatty Acid or Oxidative Metabolism in Brown Adipose Tissue of Subjects With Type 2 Diabetes. Diabetes (2015) Jul64(7):2388-97. doi: 10.2337/db14-1651

34. Eckel RH, York DA, Rössner S, Hubbard V, Caterson I, St Jeor ST, et al. American Heart Association. Prevention Conference VII: Obesity, a Worldwide Epidemic Related to Heart Disease and Stroke: Executive Summary. Circulation. (2004) 110 (18):2968-75. doi: 10.1161/01.CIR.0000140086.88453.9A

35. Cannon B, Nedergaard J. Brown Adipose Tissue: Function and Physiological Significance. Physiol Rev (2004) 84(1):277-359. doi: 10.1152/physrev. 00015.2003

36. Ali Khan A, Hansson J, Weber P, Foehr S, Krijgsveld J, Herzig S, et al. Comparative Secretome Analyses of Primary Murine White and Brown Adipocytes Reveal Novel Adipokines. Mol Cell Proteomics (2018) 17 (12):2358-70. doi: 10.1074/mcp.RA118.000704

37. Burýsek L, Houstek J. Beta-Adrenergic Stimulation of Interleukin-1alpha and Interleukin-6 Expression in Mouse Brown Adipocytes. FEBS Lett (1997) 411 (1):83-6. doi: 10.1016/s0014-5793(97)00671-6

38. Bersell K, Arab S, Haring B, Kühn B. Neuregulin1/Erbb4 Signaling Induces Cardiomyocyte Proliferation and Repair of Heart Injury. Cell. (2009) 138 (2):257-70. doi: 10.1016/j.cell.2009.04.060

39. Schumacher MA, Hedl M, Abraham C, Bernard JK, Lozano PR, Hsieh JJ, et al. Erbb4 Signaling Stimulates Pro-Inflammatory Macrophage Apoptosis and Limits Colonic Inflammation. Cell Death Dis (2017) 8(2):e2622. doi: 10.1038/ cddis. 2017.42

40. Tie G, Yan J, Yang Y, Park BD, Messina JA, Raffai RL, et al. Oxidized LowDensity Lipoprotein Induces Apoptosis in Endothelial Progenitor Cells by Inactivating the Phosphoinositide 3-Kinase/Akt Pathway. J Vasc Res (2010) 47 (6):519-30. doi: 10.1159/000313879

41. Planavila A, Redondo I, Hondares E, Vinciguerra M, Munts C, Iglesias R, et al. Fibroblast Growth Factor 21 Protects Against Cardiac Hypertrophy in Mice. Nat Commun (2013) 4:2019. doi: 10.1038/ncomms3019

42. Kotch C, Barrett D, Teachey DT. Tocilizumab for the Treatment of Chimeric Antigen Receptor T Cell-Induced Cytokine Release Syndrome. Expert Rev Clin Immunol (2019) Aug15(8):813-22. doi: 10.1080/1744666X.2019.1629904

43. Stanford KI, Middelbeek RJ, Townsend KL, An D, Nygaard EB, Hitchcox KM, et al. Brown Adipose Tissue Regulates Glucose Homeostasis and Insulin Sensitivity. J Clin Invest (2013) Jan123(1):215-23. doi: 10.1172/JCI62308

44. Qing H, Desrouleaux R, Israni-Winger K, Mineur YS, Fogelman N, Zhang C, et al. Origin and Function of Stress-Induced IL-6 in Murine Models. Cell. (2020) 182(2):372-87.e14. doi: 10.1016/j.cell.2020.05.054

45. Nandi D, Mishra MK, Basu A, Bishayi B. Protective Effects of Interleukin-6 in Lipopolysaccharide (LPS)-Induced Experimental Endotoxemia are Linked to Alteration in Hepatic Anti-Oxidant Enzymes and Endogenous Cytokines. Immunobiology (2010) 215(6):443-51. doi: 10.1016/j.imbio.2009.08.003

46. Pellegrinelli V, Peirce VJ, Howard L, Virtue S, Türei D, Senzacqua M, et al. Adipocyte-Secreted BMP8b Mediates Adrenergic-Induced Remodeling of the Neuro-Vascular Network in Adipose Tissue. Nat Commun (2018) 9(1):4974. doi: $10.1038 / \mathrm{s} 41467-018-07453-\mathrm{x}$ 
47. Rahimzadeh M, Farshidi N, Naderi N, Farshidi H, Montazerghaem H. Clinical Significance of Serum Concentrations of Neuregulin-4, in Acute Coronary Syndrome. Sci Rep (2020) 10(1):5797. doi: 10.1038/s41598-020-62680-x

48. Cereijo R, Gavaldà-Navarro A, Cairó M, Quesada-López T, Villarroya J, Morón-Ros S, et al. CXCL14, a Brown Adipokine That Mediates Brown-Fatto-Macrophage Communication in Thermogenic Adaptation. Cell Metab (2018) 28(5):750-63. doi: 10.1016/j.cmet.2018.07.015

49. Campderrós L, Moure R, Cairó M, Gavaldà-Navarro A, Quesada-López T, Cereijo R, et al. Brown Adipocytes Secrete GDF15 in Response to Thermogenic Activation. Obes (Silver Spring) (2019) 27(10):1606-16. doi: 10.1002/ oby. 22584

50. Pinckard KM, Shettigar VK, Wright KR, Abay E, Baer LA, Vidal P, et al. A Novel Endocrine Role for the BAT-Released Lipokine 12,13-Dihome to Mediate Cardiac Function. Circulation (2021) 143(2):145-59. doi: 10.1161/ CIRCULATIONAHA.120.049813

51. Barrett-Connor EL. Obesity, Atherosclerosis, and Coronary Artery Disease. Ann Intern Med (1985) 103(6(6 ( Pt 2):1010-9. doi: 10.7326/0003-4819-1036-1010

52. Yeh TL, Chen HH, Tsai SY, Lin CY, Liu SJ, Chien KL. The Relationship Between Metabolically Healthy Obesity and the Risk of Cardiovascular Disease: A Systematic Review and Meta-Analysis. J Clin Med (2019) 8 (8):1228. doi: $10.3390 / \mathrm{jcm} 8081228$

53. Krauss RM, Winston M, Fletcher BJ, Grundy SM. Obesity : Impact on Cardiovascular Disease. Circulation. (1998) 98(14):1472-6. doi: 10.1161/ 01.CIR.98.14.1472

54. Warnes CA, Roberts WC. The Heart in Massive (More Than 300 Pounds or 136 Kilograms) Obesity: Analysis of 12 Patients Studied At Necropsy. Am J Cardiol (1984) 54(8):1087-91. doi: 10.1016/s0002-9149(84)80149-6

55. de Divitiis O, Fazio S, Petitto M, Maddalena G, Contaldo F, Mancini M. Obesity and Cardiac Function. Circulation (1981) 64(3):477-82. doi: 10.1161/ 01.cir.64.3.477

56. de Simone G, Devereux RB, Mureddu GF, Roman MJ, Ganau A, Alderman $\mathrm{MH}$, et al. Influence of Obesity on Left Ventricular Midwall Mechanics in Arterial Hypertension. Hypertension (1996) 28(2):276-83. doi: 10.1161/ 01.hyp.28.2.276

57. Betz MJ, Enerbäck S. Human Brown Adipose Tissue: What We Have Learned So Far. Diabetes (2015) 64(7):2352-60. doi: 10.2337/db15-0146

58. Franssens BT, Hoogduin H, Leiner T, van der Graaf Y, Visseren FLJ. Relation Between Brown Adipose Tissue and Measures of Obesity and Metabolic Dysfunction in Patients With Cardiovascular Disease. J Magn Reson Imaging (2017) 46(2):497-504. doi: 10.1002/jmri.25594

59. Cittadini A, Mantzoros CS, Hampton TG, Travers KE, Katz SE, Morgan JP, et al. Cardiovascular Abnormalities in Transgenic Mice With Reduced Brown Fat: An Animal Model of Human Obesity. Circulation (1999) 100(21):217783. doi: 10.1161/01.cir.100.21.2177

60. Takx RA, Ishai A, Truong QA, MacNabb MH, Scherrer-Crosbie M, Tawakol A. Supraclavicular Brown Adipose Tissue 18F-FDG Uptake and Cardiovascular Disease. J Nucl Med (2016) 57(8):1221-5. doi: 10.2967/ jnumed.115.166025

61. Becher T, Palanisamy S, Kramer DJ, Eljalby M, Marx SJ, Wibmer AG, et al. Brown Adipose Tissue is Associated With Cardiometabolic Health. Nat Med (2021) 27(1):58-65. doi: 10.1038/s41591-020-1126-7

62. Moore KJ, Sheedy FJ, Fisher EA. Macrophages in Atherosclerosis: A Dynamic Balance. Nat Rev Immunol (2013) 13(10):709-21. doi: 10.1038/nri3520

63. Huh JY, Park YJ, Ham M, Kim JB. Crosstalk Between Adipocytes and Immune Cells in Adipose Tissue Inflammation and Metabolic Dysregulation in Obesity. Mol Cells (2014) 37(5):365-71. doi: 10.14348/ molcells.2014.0074

64. Wang H, Wang Q, Venugopal J, Wang J, Kleiman K, Guo C, et al. ObesityInduced Endothelial Dysfunction is Prevented by Neutrophil Extracellular Trap Inhibition. Sci Rep (2018) 8(1):4881. doi: 10.1038/s41598-018-23256-y

65. Berbée JF, Boon MR, Khedoe PP, Bartelt A, Schlein C, Worthmann A, et al. Brown Fat Activation Reduces Hypercholesterolaemia and Protects From Atherosclerosis Development. Nat Commun (2015) 6:6356. doi: 10.1038/ ncomms7356

66. Nisoli E, Clementi E, Paolucci C, Cozzi V, Tonello C, Sciorati C, et al. Mitochondrial Biogenesis in Mammals: The Role of Endogenous Nitric Oxide. Science (2003) 299(5608):896-9. doi: 10.1126/science.1079368
67. Wenz T. Mitochondria and PGC-1 $\alpha$ in Aging and Age-Associated Diseases. J Aging Res (2011) 2011:810619. doi: 10.4061/2011/810619

68. Xiong S, Salazar G, Patrushev N, Ma M, Forouzandeh F, Hilenski L, et al. Peroxisome Proliferator-Activated Receptor $\Gamma$ Coactivator- $1 \alpha$ is a Central Negative Regulator of Vascular Senescence. Arterioscler Thromb Vasc Biol (2013) 33(5):988-98. doi: 10.1161/ATVBAHA.112.301019

69. Xing X, Li Z, Yang X, Li M, Liu C, Pang Y, et al. Adipose-Derived Mesenchymal Stem Cells-Derived Exosome-Mediated Microrna-342-5p Protects Endothelial Cells Against Atherosclerosis. Aging (Albany NY) (2020) 12(4):3880-98. doi: 10.18632/aging.102857

70. Okamoto Y, Kihara S, Ouchi N, Nishida M, Arita Y, Kumada M, et al. Adiponectin Reduces Atherosclerosis in Apolipoprotein E-Deficient Mice. Circulation (2002) 106(22):2767-70. doi: 10.1161/01.cir.0000042707. 50032.19

71. Raggi P. Epicardial Adipose Tissue as a Marker of Coronary Artery Disease Risk. J Am Coll Cardiol (2013) 61(13):1396-7. doi: 10.1016/j.jacc.2012.12.028

72. Chechi K, Blanchard PG, Mathieu P, Deshaies Y, Richard D. Brown Fat Like Gene Expression in the Epicardial Fat Depot Correlates With Circulating HDL-Cholesterol and Triglycerides in Patients With Coronary Artery Disease. Int J Cardiol (2013) 167(5):2264-70. doi: 10.1016/j.ijcard.2012.06.008

73. Chechi K, Voisine P, Mathieu P, Laplante M, Bonnet S, Picard F, et al. Functional Characterization of the Ucp1-Associated Oxidative Phenotype of Human Epicardial Adipose Tissue. Sci Rep (2017) 7(1):15566. doi: 10.1038/ s41598-017-15501-7

74. van Dam AD, Boon MR, Berbée JFP, Rensen PCN, van Harmelen V. Targeting White, Brown and Perivascular Adipose Tissue in Atherosclerosis Development. Eur J Pharmacol (2017) 816:82-92. doi: 10.1016/ j.ejphar.2017.03.051

75. Sakalihasan N, Michel JB, Katsargyris A, Kuivaniemi H, Defraigne JO, Nchimi A, et al. Abdominal Aortic Aneurysms. Nat Rev Dis Primers (2018) 4(1):34. doi: 10.1038/s41572-018-0030-7

76. Nieves DJ, Cnop M, Retzlaff B, Walden CE, Brunzell JD, Knopp RH, et al. The Atherogenic Lipoprotein Profile Associated With Obesity and Insulin Resistance is Largely Attributable to Intra-Abdominal Fat. Diabetes (2003) 52(1):172-9. doi: 10.2337/diabetes.52.1.172

77. Police SB, Thatcher SE, Charnigo R, Daugherty A, Cassis LA. Obesity Promotes Inflammation in Periaortic Adipose Tissue and Angiotensin IIInduced Abdominal Aortic Aneurysm Formation. Arterioscler Thromb Vasc Biol (2009) 29(10):1458-64. doi: 10.1161/ATVBAHA.109.192658

78. Dowal L, Parameswaran P, Phat S, Akella S, Majumdar ID, Ranjan J, et al. Intrinsic Properties of Brown and White Adipocytes Have Differential Effects on Macrophage Inflammatory Responses. Mediators Inflamm (2017) 2017:9067049. doi: 10.1155/2017/9067049

79. Mechanick JI, Zhao S, Garvey WT. The Adipokine-Cardiovascular-Lifestyle Network: Translation to Clinical Practice. J Am Coll Cardiol (2016) 68 (16):1785-803. doi: 10.1016/j.jacc.2016.06.072

80. Ruan CC, Kong LR, Chen XH, Ma Y, Pan XX, Zhang ZB, et al. A2A Receptor Activation Attenuates Hypertensive Cardiac Remodeling Via Promoting Brown Adipose Tissue-Derived FGF21. Cell Metab (2020) 632(4):689. doi: 10.1016/j.cmet.2020.08.018

81. Thoonen R, Ernande L, Cheng J, Nagasaka Y, Yao V, Miranda-Bezerra A, et al. Functional Brown Adipose Tissue Limits Cardiomyocyte Injury and Adverse Remodeling in Catecholamine-Induced Cardiomyopathy. J Mol Cell Cardiol (2015) 84:202-11. doi: 10.1016/j.yjmcc.2015.05.002

82. Sihag S, Cresci S, Li AY, Sucharov CC, Lehman JJ. PGC-1alpha and Erralpha Target Gene Downregulation is a Signature of the Failing Human Heart. J Mol Cell Cardiol (2009) 46(2):201-12. doi: 10.1016/j.yjmcc.2008.10.025

83. Planavila A, Iglesias R, Giralt M, Villarroya F. Sirt1 Acts in Association With Ppar $\alpha$ to Protect the Heart From Hypertrophy, Metabolic Dysregulation, and Inflammation. Cardiovasc Res (2011) 90(2):276-84. doi: 10.1093/cvr/cvq376

84. Lv J, Deng C, Jiang S, Ji T, Yang Z, Wang Z, et al. Blossoming 20: The Energetic Regulator's Birthday Unveils Its Versatility in Cardiac Diseases. Theranostics (2019) 9(2):466-76. doi: 10.7150/thno.29130

85. Dong M, Yang X, Lim S, Cao Z, Honek J, Lu H, et al. Cold Exposure Promotes Atherosclerotic Plaque Growth and Instability Via UCP1-Dependent Lipolysis. Cell Metab (2013) 18(1):118-29. doi: 10.1016/j.cmet.2013.06.003

86. Sui W, Li H, Yang Y, Jing X, Xue F, Cheng J, et al. Bladder Drug Mirabegron Exacerbates Atherosclerosis Through Activation of Brown Fat-Mediated 
Lipolysis. Proc Natl Acad Sci USA (2019) 116(22):10937-42. doi: 10.1073/ pnas. 1901655116

Conflict of Interest: The authors declare that the research was conducted in the absence of any commercial or financial relationships that could be construed as a potential conflict of interest.
Copyright $\odot 2021$ Chen, Meng, Gao and Ruan. This is an open-access article distributed under the terms of the Creative Commons Attribution License (CC BY). The use, distribution or reproduction in other forums is permitted, provided the original author(s) and the copyright owner(s) are credited and that the original publication in this journal is cited, in accordance with accepted academic practice. No use, distribution or reproduction is permitted which does not comply with these terms. 